\title{
El verbo en el Arte de la lengua española castellana de Gonzalo Correas
}

\author{
Luis Alberto HERNANDO CUADRADO \\ Universidad Complutense de Madrid \\ lahernando@filol.ucm.es
}

\begin{abstract}
RESUMEN
El marco general de la doctrina de Gonzalo Correas sobre el verbo está en la línea de Dionisio de Tracia y los gramáticos latinos. En la tradición gramatical española, Nebrija es el autor que más influye en Correas. Sin embargo, entre ambos gramáticos hay una diferencia de enfoque, ya que Nebrija explica los fenómenos con mayor brevedad y Correas los trata más detalladamente. Por otro lado, el humanista extremeño presta atención a las formas vulgares y dialectales, y a veces indica si los fenómenos están vigentes o no en la época y el nivel social en el que son empleados.
\end{abstract}

Palabras clave: Gonzalo Correas, verbo, tradición gramatical, variedades lingüísticas

[Recibido, octubre 2010; aprobado, diciembre 2010]

\section{The verb in Arte de la lengua española castellana, by Gonzalo Correas}

\begin{abstract}
The general frame of Gonzalo Correas' doctrine on the verb is in the line of Dionysus Thrax and the Latin grammarians. In the Spanish grammatical tradition, Nebrija is the author who influences more on Correas. Nevertheless, there is a difference of focus between them because Nebrija explains the phenomena in a brief way and Correas does it more detailedly. On the other hand, the Extremaduran humanist pays attention to the vulgar and dialectal forms and sometimes he indicates if the phenomena are in force or not in the epoch and the social level in which are used.
\end{abstract}

Keywords: Gonzalo Correas, verb, grammatical tradition, linguistic varieties

1. Gonzalo Correas, aunando los criterios semántico y morfológico, en la línea de Dionisio de Tracia, los gramáticos latinos Donato, Carisio, Diomedes y Prisciano, Nebrija en las Introductiones y otros tratadistas del español de su época, como C. de Villalón, R. Percyvall, J. de Luna y Fray D. de la Encarnación, define el verbo como "aquella palavra que sinifica el hazer i obrar, i dezir las cosas i ser hechas, i obradas, i dezirse: i tiene boz i conxugazion"1.

${ }^{1}$ G. Correas, Arte de la lengua española castellana. Edición y prólogo de E. Alarcos García, Madrid, CSIC, Instituto "Miguel de Cervantes", Anejo LVI de la RFE, 1954, fols. 97 v.-98 r. En la caracterización del verbo en el mundo clásico habían solido mezclarse, en efecto, los criterios morfológico y se- 
Con el tiempo, la Real Academia Española, por ejemplo, habiéndose basado en la definición de verbo hasta la edición de 1867 solamente en el aspecto semántico, desde la de 1870 tendrá en cuenta también el morfológico ${ }^{2}$, y en la de 1917 formulará su redacción definitiva en los siguientes términos: "Verbo es una parte de la oración que designa estado, acción o pasión, casi siempre con expresión de tiempo y de persona" 3 .

En nuestros días, el verbo, núcleo del grupo sintagmático verbal, es presentado en los estudios gramaticales como la categoría por antonomasia en las lenguas románicas, en general, y en la española, en particular, por atesorar una riqueza de contenido que ninguna otra parte de la oración posee, ya que en él se encuentran condensados los dos campos esenciales del lenguaje (el simbólico, representado en el lexema, y el deíctico, en los morfemas de persona y número), así como varios tipos de medidas de tiempo, que forman un entramado de momentos y

mántico. La definición de Dionisio de Tracia como una "parte de la oración sin flexión de caso, pero con flexión de tiempo, persona y número, y que significa una actividad o proceso realizado o experimentado" (R. H. Robins, Breve historia de la Lingüistica, Madrid, Paraninfo, 1992, p. 51) constituye la base de las formuladas por los gramáticos latinos Donato ("Pars orationis cum tempore et persona sine casu aut agere aliquid aut pati aut neutrum significans" [H. Keil (ed.), Grammatici Latini, IV, Hildesheim - New York, G. Olms, 1981, p. 359]), Carisio ("pars orationis administrationem rei significans cum tempore et persona numerisque carens casu" [H. Keil (ed.), I, p. 164]), Diomedes ("pars orationis praecipua sine casu. Etenim haec universae orationi uberes praebet ad facultatem vires. Cuius operae pretium penitus intueri potestatem, nec inscita vitiosum exerceamus sermonem. Vis igitur huius temporibus et personis administratur" [H. Keil (ed.), I, p. 334]) y Prisciano, que no menciona la persona y añade el modo: "pars orationis cum temporibus et modis, sine casu, agendi vel patiendi significativum" (H Keil [ed.], II, p. 369). Nebrija, en las Introductiones, reproduce casi literalmente la definición de Prisciano, agregando el adjetivo declinabilis: "Pars orationis declinabilis cum modis et temporibus sine casu agendi uel patiendi significatiua" (Introducciones latinas contrapuesto el romance al latín [c. 1488]. M. A. Esparza \& V. Calvo [eds.], Münster, Nodus Publikationen, 1996, fol. 41 r.). Entre los seguidores de esta corriente, además de G. Correas, se encuentran C. de Villalón, R. Percyvall, J. de Luna y Fray D. de la Encarnación, que publicaron sus obras antes que él el Arte. Sin embargo, F. Sánchez de las Brozas, al definir el verbo, se centra solamente en su aspecto puramente gramatical, presentándolo como la palabra que tiene número, persona y tiempo: "Verbum est uox particeps numeri personalis cum tempore" (Minerva o De causis linguae latinae. Introducción y edición de E. Sánchez Salor [Libri I, III y IV]; edición de C. Chaparro Gómez [Liber II], Cáceres, Institución Cultural "El Brocense", Excma. Diputación Provincial de Cáceres y Universidad de Extremadura, 1995, p. 27 v.). A. Bello, con un enfoque lógico-gramatical, lo interpreta como "una clase de palabras que significan el atributo de la proposición, indicando juntamente la persona y número del sujeto, el tiempo y Modo del atributo" (Gramática de la lengua castellana destinada al uso de los americanos. Con las Notas de R. J. Cuervo. Estudio y edición de R. Trujillo, Madrid, Arco/Libros, 1988, § 476).

${ }^{2}$ En la definición del verbo de la Real Academia Española en la edición de 1870 se citan menos rasgos semánticos que en las anteriores (solo los de acción y estado) y los accidentes gramaticales de tiempo y persona: "Verbo es una parte de la oracion que designa accion ó estado, con expresion de tiempo y persona" (Gramática de la lengua castellana, Madrid, Imprenta y estereotipia de M. Rivadeneyra, 1870, p. 50).

${ }^{3}$ Real Academia Española, Gramática de la lengua castellana, Madrid, Perlado, Páez y Compañía (Sucesores de Hernando), Impresores y Libreros de la Real Academia Española, 1917, p. 39. 
perspectivas, y la actitud del hablante ante el enunciado (mediante los morfemas de tiempo, modo y aspecto).

Del mismo modo que Nebrija, bajo la influencia de los gramáticos grecolatinos, especialmente Prisciano, Correas reconoce en esta parte de la oración ocho accidentes: género, especie, figura, tiempo, persona, número, modo y conjugación ${ }^{4}$.

Por el género, sostiene nuestro gramático que todos los verbos del castellano son activos, ya que "sinifican hazer alguna cosa", y se subdividen en transitivos, los "activos que pasan en la cosa que dizen, i declaran": leo los libros, oigo las lecciones, pido merced; intransitivos, absolutos o neutros, los que "no pasan en otra cosa, antes en si mesmos se queda, i cunple su sinificazion entera, i llena": duermo, río, vivo; e impersonales, con los que "no se declara quien haze, i pareze que van sin la persona biviente agente que los aconpañe, i determine, ni en el hablar se echa menos, ni se busca"8: llueve, conviene, importa.

Los verbos transitivos pueden comportarse ocasionalmente como intransitivos, "sin pasar à la cosa que declaran"9 (escribo, como, bebo), y los intransitivos, como transitivos, si se les añade "la cosa que sinifican"10: vivo vida trabajosa, duermo sueño pesado, ando caminos largos. Del mismo modo, los impersonales se emplean a veces como personales (llovía Dios a cántaros, partí de madrugada y amanecí en la arada, estuve bueno todo el día y anochecí con gran calentura), y los personales,

${ }^{4}$ G. Correas, Arte, fol. 121 v. Nebrija, siguiendo a Prisciano, que señala que "verbo accidunt octo: significatio sive genus, tempus, modus, species, figura, coniugatio, et persona cum numero" (H. Keil [ed.], II, p. 369), reconoce ocho accidentes en el verbo, tanto en las Introductiones ("Verbo quot accidunt? // Octo: genus, modus, tempus, numerus, persona, species, figura, coniugatio" [fol. $41 \mathrm{r}$.]) como en la Gramática: "Los accidentes del verbo son ocho: especie, figura, género, modo, tiempo, número, persona y conjugación" (Gramática de la lengua castellana. Edición crítica de A. Quilis, Madrid, Ediciones de Cultura Hispánica, 1992, fol. 37 v.). Los ocho accidentes mencionados por Prisciano y Nebrija son los que aparecen en Dionisio de Tracia. Ocho es el número de accidentes verbales que se registra igualmente en los gramáticos latinos Diomedes y Carisio (Donato y Consentio hablan de siete, y Probo, de nueve).

${ }^{5}$ G. Correas, Arte, fol. 99 v.

${ }^{6}$ G. Correas, Arte, fol. 99 v.

${ }^{7}$ G. Correas, Arte, fol. 99 v.

${ }^{8}$ G. Correas, Arte, fol. 100 r. Nebrija, en las Introductiones, menciona los cinco géneros más frecuentes en las clasificaciones de los gramáticos latinos, entre ellos Prisciano ("Genera uerborum quot sunt? // Quinque: actiuum, passiuum, neutrum, deponens, commune" [fol. 41 r.]) y, en la Gramática, apunta que el género es "aquello por que se distingue el verbo activo del absoluto" (fol. 37 v.). En el mundo griego, Dionisio de Tracia había reconocido la existencia de tres voces, activa, pasiva y media. Para F. Sánchez de las Brozas, que rechaza la postura de los gramáticos latinos, todos los verbos son activos o pasivos:

Grammatici nescio quo errore inducti uerba omnia in quinque genera diuiserunt: actiuum, passiuum, neutrum, commune, deponens. Nobis auntem, inquit Caesar Scaliger, satis sit uniuersum uerborum ambitum in duo diuidere, quae actionem et passionem significent, quemadmodum horum utrumque ad unum, quippe ad ipsum 'Est', quod est utriusque radix et fundamentum. Hanc Scaligeri rationem sic confirmare possumus: Philosophia, id est, recta et incorrupta iudicandi ratio, nullum concedit medium inter agere et pati; omnis namque motus aut actio est aut passio; imo, si rem penitus inspicias, actio et passio nihil differunt nisi ratione quadam, sicut accliue et decliue. Id quod docet Aristoteles, 3 Physic., cap. 3 (Minerva, pp. 89-89 v.).

${ }^{9}$ G. Correas, Arte, fol. 99 v.

${ }^{10}$ G. Correas, Arte, fol. 99 v. 
como impersonales, en la tercera persona del plural (allí juegan, aqui leen, en la plaza corren) o en la tercera del singular con la partícula se (ámase, léese, hácese tarde), teniendo en este caso significación "pasiva, ò casi pasiva""

Aunque, frente al latín, griego y hebreo, el castellano carece de la voz pasiva, no por ello deja de expresar "todo lo que se ofreze pasivo cunplidamente i con mucha eleganzia i grazia"12. Según Correas, nuestra lengua suple la pasiva con perífrasis constituidas por la combinación de ser + participio pasado: yo soy amado, tú serías amado, aquél había sido amado; con los pronombres me, te, se, en singular, y nos, $o s$, se, en plural, "xuntandose con las cadenzias ò personas verbales de su numero i persona" ": consúmome, Sancho se murió, en la plaza se corren toros; con estar + gerundio (forma verbal a la que el autor llama "infinitivo de modo i partizipial"14) y los citados pronombres, pospuestos a estar (estámonos consumiendo) o antepuestos: por la calle se está holgando; o con ir + gerundio y los pronombres mencionados, ligados a ir (voyme mojando) o al gerundio: secándome voy ${ }^{15}$. Como se ve, la pasiva refleja no queda deslindada de los verbos pronominales ${ }^{16}$.

Después de Correas, en el mismo siglo XVII, la Grammaire de Port-Royal generalizará la concepción de la pasiva por considerar que "les langues vulgaires de l'Europe n'ont point de passif, et elles se servent au lieu de cela, d'un participe fait du Verbe actif, qui se prend en sens passif, avec le verbe substantif ${ }^{\prime 17}$. En el siglo XIX y primeras décadas del $\mathrm{XX}$, dada la creciente importancia otorgada a partir del siglo XVIII a los criterios de índole nocional o por la necesidad de codificar la especificidad sintáctica de las construcciones pasivas, se va incorporando progresivamente en las gramáticas del español la voz pasiva como uno de los accidentes de la conjugación verbal.

${ }^{11}$ G. Correas, Arte, fol. 100 v.

${ }^{12}$ G. Correas, Arte, fol. 108 v.

${ }^{13} \mathrm{G}$. Correas, Arte, fol. $111 \mathrm{r}$.

${ }^{14}$ G. Correas, Arte, fol. 111 r.

${ }^{15}$ En ambos casos, el conglomerado constituido por la forma verbal en cuestión y el pronombre átono ocupa el primer lugar dentro del conjunto.

${ }^{16}$ Nebrija hace hincapié en la Gramática en que en español, frente al latín, solo existe la voz activa ("El latín tiene tres bozes: activa, verbo impersonal, passiva; el castellano no tiene sino sola el activa" [fol. $38 \mathrm{v}$.]), aunque la pasiva latina pueda suplirse por medio de la perífrasis $s e r+$ participio pasado del verbo que se conjuga ("La passiva suple la por este verbo so, eres i el participio del tiempo passado de la passiva mesma" [fol. $38 \mathrm{v}$.]) (io so amado, io era amado, io seré amado) o por la tercera persona de dicho verbo en voz activa acompañado de la forma pronominal átona se ("Dize esso mesmo las terceras personas de la boz passiva por las mesmas personas de la boz activa, haziendo retorno con este pronombre se" [fol. 39 r.]): ámase Dios; ámanse las riquezas. La voz impersonal del latín, a su juicio, se expresa en nuestra lengua con la tercera persona del plural del verbo activo o con $s e+$ verbo activo en tercera persona del singular: "El verbo impersonal suple lo por las terceras personas del plural del verbo activo del mesmo tiempo i modo, o por las terceras personas del singular, haziendo reciprocación i retorno con este pronombre se" (fol. 38 v.): corren, córrese; corrían, corríase.

${ }^{17}$ A. Arnauld y C. Lancelot, Grammaire générale et raisonnée, Stuttgart-Bad Cannstatt, F. F. Verlag, 1966, p. 122. 
Posteriormente, ciertos autores, como A. Bello y M. Seco, evitan el uso del término voz $\mathrm{y}$, cuando se refieren a la pasiva, le aplican el calificativo de construcción; algunos, como S. Fernández Ramírez, hablan simplemente de pasiva; y otros, como J. Alcina y J. M. Blecua, siguen empleando la denominación tradicional pero sin atribuirle concomitancias morfológicas, ya que, a su juicio, "parece evidente que la voz no se expresa por medios morfológicos sino sintácticos y que la expresión de pasiva / no pasiva está reservada al contenido léxico del participio que mantiene la cualidad adjetiva de la concordancia" ${ }^{\prime 18}$.

Por la especie, los verbos se dividen en primitivos (amar, temer) y derivados (armar, de armas; sopear, de so y pies), y estos últimos se subdividen en seis clases, frecuentativos (de beber, beborrear, beberretear, beborretear, beborronear), aumentativos (de negrear, negrecer, ennegrecer), continuativos (amanecer, anochecer, crecer), diminutivos (de comer, comiscar; de oler, oliscar), denominativos (de golpe, golpear; de bobo, bobear, abobar, embobar) y adverbiales: de abajo, abajar; de encima, encimar; de delante, adelantar ${ }^{19}$.

Por la figura, los verbos pueden ser simples (conozco, hago) y compuestos: reconozco, deshago ${ }^{20}$. Dentro del grupo de estos últimos, Correas distingue los "venidos del Latin" 21 (convertir, sustentar), "que aca los podemos tener por sinples" 22 , y los formados en castellano, con prefijo y verbo simple (de batir, abatir; de tornar, entornar), con prefijo y verbo derivado de nombre (de palo, apalear; de ligero, aligerar) y de nombre y verbo: de mano y atar, maniatar; de pierna y quebrar, perniquebrar.

Las personas del discurso, de acuerdo con Nebrija, que sigue, a su vez, a Prisciano, son tres: la primera $(y o)$, "que habla de $\mathrm{si}^{\prime 23}$; la segunda (tú), "à la qual

${ }^{18}$ J. Alcina franch y J. M. Blecua, Gramática Española, $11^{\mathrm{a}}$ ed., Barcelona, Ariel, 2001, § 5.4.1.

${ }^{19}$ Nebrija, en las Introductiones, partiendo de la idea de que las especies, como en el nombre, son dos, "primitiua, ut lego; deriuatiua, ut lectito" (42 r.), enumera siete subclases de esta última, "inchoatiua, meditatiua, desideratiua, frequentatiua, diminutiua, denominatiua, aduerbialia" (42 r.); sin embargo, en la Gramática, tras distinguir igualmente dos especies, "primogénita" (fol. 37 v.) (amar) y derivada (armar, de armas), dentro de la segunda incluye cuatro subtipos, aumentativos (blanquecer, de blanquear), diminutivos (baticar, de batir), denominativos (acuchillar, de cuchillo) y adverbiales: encimar, de encima. Prisciano, aprovechando la enseñanza de Dionisio de Tracia, había puntualizado que "species sunt verborum duae, primitiva et derivativa, quae inveniuntur fere in omnibus partibus orationis. Est igitur primitiva, quae primam positionem ab ipsa natura accepit, ut lego, ferveo, domo, facio, garrio, albo; derivativa, quae a positivis derivantur, ut lecturio, fervesco, domito, facesso, garrulo, albico" $(\mathrm{H}$. Keil [ed.], II, p. 427).

${ }^{20}$ Para Nebrija, las figuras, también como en el nombre, son dos, "Simplex, ut amo. Composita, ut deamo", en las Introductiones (fol. 43 r.), "senzilla" (amar) y compuesta (desamar), en la Gramática (fol. 37 v.). Prisciano, como antes Dionisio de Tracia, en relación con las figuras, había manifestado que "alia enim verborum sunt simplicia, ut cupio, taceo, alia composita, ut concupio, conticeo, alia decomposita, id est a compositis derivata, ut concupisco, conticesco" (H. Keil [ed.], II, p. 434).

${ }^{21}$ G. Correas, Arte, fol. 120 v.

${ }^{22} \mathrm{G}$. Correas, Arte, fol. $120 \mathrm{v}$.

${ }^{23}$ G. Correas, Arte, fol. 99 r. 
habla la primera" 24 , y la tercera (aquél), "de la qual habla la primera y segunda" 25 . En el verbo, las personas se expresan mediante "las cadenzias ò terminaziones que tienen los tienpos, tres en singular, i tres en plural" ${ }^{\prime 2}$.

Como la mayor parte de los gramáticos latinos, Nebrija, C. de Villalón, G. Miranda, R. Percyvall, C. Oudin, J. A. Zumarán, Correas indica que "los numeros son dos, como en el nonbre: numero de uno ò de singular, i número de muchos ò plural"27. De esta manera, a excepción de los defectivos, los verbos castellanos poseen tres formas en singular y tres en plural, una para cada una de las tres personas del discurso ${ }^{28}$.

${ }^{24}$ G. Correas, Arte, fol. 99 r.

${ }^{25}$ G. Correas, Arte, fol. 99 v.

${ }^{26}$ G. Correas, Arte, fol. 99 r. Desde la antigüedad grecolatina, los gramáticos reconocen unánimemente la existencia de tres personas. Nebrija, si bien sigue en general la tradición en sus Introductiones, se aparta de ella al considerar el accidente de persona como un elemento no solo del verbo, sino también del nombre y del pronombre: "Personae nominum, pronominum et uerborum tres sunt: prima ut ego amo, secunda ut tu amas, tertia ut ille amat" (fol. 14 r.). Por el contrario, F. Sánchez de las Brozas, teniendo en cuenta que, como observan los gramáticos, los nominativos son de tercera persona, excepto ego, que es de primera, y $t u$, de segunda, puntualiza que la persona se halla incluida en la desinencia verbal como uno de los elementos constituyentes del verbo:

proprie terminationes illae uerbales dicuntur facies. Nominatiua enim personam non habent, sed sunt alicuius personae uerbalis; et uero recte enuntiant grammatici: omnis nominatiuus est tertiae personae, praeterquam ego, quod est primae, et $t u$, quod est secundae (Minerva, p. 28).

Prisciano había manifestado que:

sunt igitur personae verborum tres. Prima est quae de se loquitur vel sola vel cum aliis, ut dico, dicimus, secunda, ad quam loquitur, de ipsa vel sola vel cum aliis, ut dicis, dicitis, tertia, de qua extra se et illam, ad quam dirigit sermonem, posita loquitur prima, ut dicit, dicunt. Et prima quidem et secunda verborum personae finitae sunt, praesentes enim demonstrantur, tertia vero infinita est itaque eget plerumque pronomine ut definiatur (H. Keil [ed.], II, p. 448).

Nebrija, en las Introductiones, siguiendo a Prisciano, escribe: "Personae uerborum quot sunt? Tres. Prima quae de se sola uel de se cum aliis loquitur, ut ego amo, nos amamus. Secunda ad quam solam uel cum aliis prima loquitur, ut tu amas, uos amatis. Tercia de qua sola uel de quibus prima loquitur, ut Cicero legit, homines legunt" (fol. 42 r.), y, en la Gramática, enseña igualmente que "las personas son tres: primera, que habla de sí; segunda, a la cual habla la primera; tercera, de la cual habla la primera" (fol. 58 v.). Como Nebrija, los tratadistas de los siglos XVI y XVII G. Miranda, R. Percyvall, C. Oudin, A. de Salazar, Fray D. de la Encarnación, G. Correas y J. A. Zumarán repiten la idea de que las personas del verbo son tres. Los restantes gramáticos coinciden en este punto como se observa en sus paradigmas verbales. Desde entonces, salvo en algún leve matiz, la doctrina sobre el particular no ha cambiado prácticamente.

${ }^{27}$ G. Correas, fol. $99 \mathrm{v}$.

${ }^{28}$ La mayor parte de los gramáticos latinos (Donato, Carisio, Diomedes, Consentio y Prisciano) había señalado que los números de los verbos son dos, singular y plural. Según Prisciano, por ejemplo, "numerus accidit verbis uterque, quomodo et omnibus casualibus, singularis, ut lego, pluralis, ut legimus" (H. Keil [ed.], II, p. 451). En este contexto, Nebrija reconoce asimismo dos números en los verbos, tanto en las Introductiones ("Numeri uerborum quot sunt? Duo sicut in nomine. Singularis, qui de uno loquitur, ut amo. Pluralis, qui de pluribus loquitur, ut amamus" [fol. 42 r.]) como en la Gramática: "Los números en el verbo son dos, assí como en el nombre: singular como diziendo io amo; plural, como nos amamos" (fol. 38 v.). Aunque solo C. de Villalón, G. Miranda, R. Percyvall, C. Oudin, G. Correas y J. A. Zumarán apuntan que los números del verbo son dos, todos los demás gramáticos de la época comparten esta opinión según se comprueba en los paradigmas verbales contenidos en sus obras. 
Los cinco modos que admite Nebrija, de acuerdo con Prisciano (indicativo, subjuntivo, optativo, imperativo e infinitivo), Correas los reduce a dos, el demostrativo o indicativo, "que demuestra zierta, i libremente, i es como sustantivo, i esenzial de la orazion" 29 , y el subjuntivo, "que habla condizionalmente, i depende del demostrativo, i se le xunta como su adxetivo, i no puede estar sin él" ${ }^{30}$. El subjuntivo, "sin mudar nada de sus tienpos en letra ò terminazion"31, presenta distintos matices significativos según "la diversidad i maneras, i propositos de hablar, i las particulas que le modifican"32, pudiendo ser optativo, potencial, concesivo, deprecativo o "indefinito i vago" 33 .

Por lo que respecta a los tiempos, Correas sigue la tradición de fijar en cinco su número: el presente (llamado praesens en la gramática latina), "que demuestra lo que aora se haze" ${ }^{34}$ : amo, ame; el pasado no cumplido ni acabado (praeteritum imperfectum en la gramática latina), "que muestra lo que se hazia i no se acabó"35: amaba, amara, amaría, amase; el pasado cumplido y acabado (praeteritum perfectum en la gramática latina), "que muestra lo que se hizo, i acabó" 36 : amé, he amado, hube amado, haya amado; el pasado más que cumplido (praeteritum plusquamperfectum en la gramática latina), "que muestra que algo se hizo antes que otra cosa, i antes que otro hiziese" ${ }^{37}$ : había amado, hubiera amado, habría amado, hubiese amado; y el venidero (futurum en la gramática latina), "que muestra lo que se á de hazer adelante" $"$ amaré, he de amar, amare, habré amado, hubiere amado.

${ }^{29}$ G. Correas, Arte, fol. 99 v.

${ }^{30}$ G. Correas, Arte, fol. $99 \mathrm{v}$.

${ }^{31}$ G. Correas, Arte, fol. 99 v.

${ }^{32}$ G. Correas, Arte, fol. 99 v.

${ }^{33}$ G. Correas, Arte, fol. 99 v. En el mundo griego, Dionisio de Tracia había reconocido cinco modos, indicativo, imperativo, optativo, subjuntivo e infinitivo. Prisciano, que acepta estos cinco modos en latín ("Sunt autem quinque: indicativus sive definitivus, imperativus, optativus, subiunctivus, infinitus" [H. Keil (ed.), II, p. 421]), propone la siguiente definición del accidente de modo: "Modi sunt diversae inclinationes animi, varios eius affectus demonstrantes" (H. Keil [ed.], II, p. 421). Nebrija sigue a Prisciano, tanto en las Introductiones ("Modi uerborum quot sunt? // Quinque: indicatiuus, imperatiuus, optatiuus, subiunctiuus, infinitiuus" [fol. 41 v.]) como en la Gramática, donde comenta que el modo, llamado "calidad" (fol. 38 r.) por Quintiliano, "es aquello por lo cual se distinguen ciertas maneras de significar en el verbo" (fol. 38 r.), a lo que añade que los modos "son cinco: indicativo, imperativo, optativo, subjunctivo, infinitivo" (fol. 38 r.) Como Nebrija, nuestros gramáticos de los siglos XVI y XVII suelen aceptar que existen cinco modos en español. G. Meurier y R. Percyvall introducen el potencial, y J. Sánchez, B. Jiménez Patón y J. de Luna excluyen el optativo. Las clasificaciones de los gramáticos posteriores aparecen divididas, si bien se detecta una acusada tendencia a aceptar la de la Gramática académica, en la que se mencionan cuatro, indicativo, imperativo, subjuntivo e infinitivo, desde la edición de 1771 hasta la de 1916, y cinco, al añadirse el potencial, a partir de la de 1917. En el Esbozo se reducen a tres, indicativo, subjuntivo e imperativo.

${ }^{34}$ G. Correas, Arte, fol. 98 r.

${ }^{35}$ G. Correas, Arte, fol. 98 r.

${ }^{36}$ G. Correas, Arte, fol. 98 r.

${ }^{37}$ G. Correas, Arte, fol. 98 r.

${ }^{38}$ G. Correas, Arte, fols. 98 r.-98 v. Los gramáticos latinos distinguían cinco tiempos en los verbos, hecho que comenta Donato en los siguientes términos: "Quot sunt tempora in declinatione verborum? 
Con el precedente de Nebrija, Correas parece alumbrar la separación entre los tiempos absolutos y los tiempos relativos, señalando expresamente este último carácter en las formas del perfectum de indicativo correspondientes al pretérito anterior, que "sinifica pasado con antezedenzia de tienpo i ocasion à otra cosa, ò persona" 39 (yo llegué primero, y hube comido y dormido cuando él llegó), y al pretérito pluscuamperfecto, "con que se dize la tal prezedenzia" (cuando él arribó, había yo descansado ya y comido), así como a las del futuro de subjuntivo correspondientes a las que hoy conocemos con el nombre de futuro imperfecto de subjuntivo, que "es vago i condizional" (el que trabajare medrará), al futuro perfecto de indicativo, cuya "sinificazion es con anticipazion"42 (habré andado una legua cuando amanezca), y al futuro perfecto de subjuntivo, que "tanbien es condizional con prezedenzia" ${ }^{43}$ : quien hubiere perdido una bolsa traiga las señas $y$ dársela han.

Quinque. Quae? Praesens, ut lego, praeteritum imperfectum, ut legebam, praeteritum perfectum, ut legi, praeteritum plusquamperfectum, ut legeram, futurum, ut legam" (H. Keil [ed.], IV, p. 360). Como advierte Prisciano, los tiempos primarios eran tres, el presente, el pasado y el futuro, subdividiéndose el pasado en imperfecto, perfecto y pluscuamperfecto: "Sunt igitur tempora tria, praesens, praeteritum et futurum. Sed praeteritum rursus dividitur in tria, in praeteritum imperfectum, praeteritum perfectum, praeteritum plusquamperfectum" (H. Keil [ed.], II, p. 405). Los cinco tiempos, en las Introductiones de Nebrija, como en los gramáticos latinos, reciben, respectivamente, la denominación de "praesens, praeteritum imperfectum, praeterirum perfectum, praeteritum pluscuamperfectum, futurum" (fol. 41 v.), y, en la Gramática, la de "presente, passado no acabado, passado acabado, passado más que acabado, venidero" (fol. 38 r.). Entre los gramáticos de los siglos XVI y XVII que, sobre la base de la gramática latina, suelen distinguir, como Nebrija en la Gramática, los cinco tiempos indicados, la forma habré amado es considerada por el Anónimo de 1555, G. M. Alessandri, G. Miranda y G. Correas como futuro de subjuntivo, y como futuro de indicativo por J. Sánchez, N. Charpentier y B. Jiménez Patón. Posteriormente, en la clasificación de los tiempos predominará la basada en la de los gramáticos latinos, con la particularidad de que en el pretérito imperfecto de subjuntivo se encontraban incluidas las formas amara, amaría y amase, y en el pretérito pluscuamperfecto de dicho modo hubiera amado, habría amado y hubiese amado, fenómeno que se observa, por ejemplo, en la Gramática académica hasta la edición de 1916. En la de 1917, amaría y habría amado pasan a formar el modo potencial, simple y compuesto, respectivamente. En el Esbozo, como ya se ha indicado, tales formas pasan al modo indicativo.

${ }^{39}$ G. Correas, Arte, fol. 107 r. Como en la actualidad, Correas observa que el pretérito anterior (hube amado) se utiliza menos que el pretérito pluscuamperfecto (había amado): "Usase pocas vezes deste rrodeo, porque está mas à mano el inperfecto, con que se dize la tal prezedenzia" (Arte, fol. 107 r.).

${ }^{40}$ G. Correas, Arte, fol. 107 r.

${ }^{41}$ G. Correas, Arte, fol. 107 r.

${ }^{42}$ G. Correas, Arte, fol. 107 r.

${ }^{43}$ G. Correas, Arte, fol. 107 r. En nuestros días, al estudiar el verbo, se suele hacer notar que la actualización en el tiempo se realiza con respecto a dos puntos de referencia, el momento en que se sitúa el acto de habla y el momento en que se sitúa el significado de otra forma verbal, correspondiendo tal cometido, respectivamente, a los tiempos absolutos (el presente, futuro imperfecto, pretérito indefinido y pretérito perfecto de indicativo, y el imperativo) y a los relativos (el pretérito imperfecto, condicional simple y compuesto, pretérito pluscuamperfecto, pretérito anterior y futuro perfecto de indicativo, y todos los del subjuntivo). 
Correas diverge de Nebrija al considerar como tiempos, y no como modos, el imperativo y el infinitivo. Sobre el primero de ellos afirma que existe un tiempo para mandar "que con palavra Latina le llamamos tienpo inperativo, i en Rromanze le pudieramos llamar tienpo mandador ò mandadero, ò tienpo que manda, i no tiene mas de segunda persona de singular, i segunda plural, que es el numero de uno, i el numero de muchos. En Latin le hazen de modo inperativo sin rrazón"44.

A propósito del segundo, comenta que hay también "un tienpo infinitivo que no tiene mas de una persona vaga $i$ comun à las tres personas bivientes que hablan en anbos numeros, i por todos los tienpos, i casos" ${ }^{\$ 5}$. Este es el infinitivo de presente: amar. Para expresar tiempo pasado o venidero, explica que suplen esta forma verbal "por rrodeo otros infinitivos" "46 haber amado, haber de amar.

Además, hay un "infinitivo de modo i partizipial" "47 llamado gerundio por los gramáticos latinos (amando), que "declara la manera como algo se haze",48, y "tres partizipios" $"$, correspondientes a los tres tiempos, dos propios (el de presente [amante] y el de pasado: amado ${ }^{50}$ y uno, el de venidero, "suplido por rrodeo" ${ }^{51}$ el que amaría, el que ha de amar.

Al participio que forma parte de los tiempos compuestos (ha amado), la parte de la oración llamada nombre participial infinito por Nebrija ${ }^{52}$, Correas le aplica la denominación de "partizipio ministro" ${ }^{33}$ por servir solamente para suplir los tiempos "que se hazen por rrodeo de palavras" del que parece tomado "en la boz neutra, comun al numero de uno i al numero de muchos sin mudarse"

Las conjugaciones en castellano son tres. La primera tiene su infinitivo acabado en -ar, como amar o arar; la segunda, en -er, como tener o comer, y la tercera, en -ir,

${ }^{44}$ G. Correas, Arte, fol. 98 v.

${ }^{45}$ G. Correas, Arte, fol. 98 v.

${ }^{46}$ G. Correas, Arte, fol. 98 v.

${ }^{47}$ G. Correas, Arte, fol. 98 v.

${ }^{48}$ G. Correas, Arte, fol. 98 v. En el paradigma de la conjugación, el autor incluye otro "infinitivo de modo i partizipial" (Arte, fol. 104 v.) de pasado (habiendo amado) y otro de futuro (habiendo de amar), ambos "por rrodeo" (Arte, fol. 104 v.).

${ }^{49}$ G. Correas, Arte, fol. $98 \mathrm{v}$.

${ }^{50}$ El participio de presente y el de pasado poseen en el paradigma de la conjugación propuesto por Correas sendos suplementos, el que ama y el que amó, respectivamente.

${ }^{51}$ G. Correas, Arte, fol. 98 v.

${ }^{52}$ Acerca del nombre participial infinito, parte de la oración que en castellano "no se puede reduzir a ninguna de las otras nueve" (Gramática, fol. 41 r.) y que no existe en "el griego, latín, ebraico i arábigo" (fol. 41 r.), explica Nebrija que se llama nombre "porque significa substancia i no tiene tiempos" (fol. 41 r.); participial, "por que es semejante al participio del tiempo passado" (fol. 41 r.); e infinito, "por que no tiene géneros, ni casos, ni personas determinadas" (fol. 41 r.).

${ }^{53}$ G. Correas, Arte, fol. 98 v.

${ }^{54}$ G. Correas, Arte, fol. 98 v.

${ }^{55}$ G. Correas, Arte, fol. 98 v.

${ }^{56} \mathrm{G}$. Correas, Arte, fol. 98 v. 
como consumir o escribir. De esta manera, "los verbos se rreparten en las tres conxugaziones, i unos van por la primera, i otros por la segunda, i otros por la tercera, i ninguno por todas ò por las dos" ${ }^{\natural 7}$. La segunda y tercera "tienen muchos tienpos semexantes i los demas se diferenzian poco",58.

2. En la explicación de la formación de los tiempos, Correas, teniendo en cuenta que las reglas formuladas por los gramáticos grecolatinos son excesivamente complicadas, considera necesario sustituirlas por otras más sencillas, concordes con la idiosincrasia de nuestra lengua:

Los gramaticos enseñan en Latin i Griego unas formaziones imaxinadas por ellos, sacando unos tienpos de otros inpropiamente con aparienzia de conformidad, las quales sin ser enseñadas cada uno se las puede sin maestro colexir i fabricar por si en decorando las conxugaziones; i dexan en olvido las verdaderas i naturales que cada lengua se trae consigo notorias, i que son mas faziles i claras, i las que solamente deve enseñar el maestro, como mas propias, lexitimas y maxistrales, las cuales io enseñé sienpre en las otras lenguas i enseñaría aora en la nuestra Española ${ }^{59}$.

En el presente de indicativo, Correas observa que a los verbos dar, estar, ser e ir, en la primera persona del singular, tras la terminación, "se les añade $i$ ",60, diciéndose "doi, estoi, soi, voi" ${ }^{61}$ en vez de do, estó, so, vo, que eran las formas usadas "zien años atras" $"$ y aun alguna vez en su época. En la segunda persona del plural de los presentes de indicativo y subjuntivo, señala que los antiguos decían amades y amedes, temedes y temades, consumides y consumades, pero "de muchos años aca se cortan i contraen por sincopa en el uso comun de todos" ${ }^{\$ 3}$, diciéndose amáis y améis, teméis y temáis, consumís y consumáis.

${ }^{57}$ G. Correas, Arte, fol. 98 r.

${ }^{58}$ G. Correas, Arte, fol. 98 r. Nebrija, en las Introductiones, indica que las conjugaciones en el verbo latino son cuatro ("Coniugationes uerborum quot sunt? // Quattuor. Prima quae habet $-a$ - productam ante -re uel $-r i$ in preaesenti infinitiui, ut amare, laetari. Secunda quae habet -e-productam ante -re uel $-r i$ in infinitiuo, ut docere, tueri. Tertia quae habet -e correptam in infinitiuo ante -re uel ante -ris in secunda persona praesentis indicatiui modi, ut legere, loqueris. Quarta quae habet - $i$ - productam ante -re uel -ri in infinitiuo, ut audire, largiri" [fol. 43 r.]), y, en la Gramática, que en el verbo español son tres, la primera, "que acaba el presente del infinitivo en $a r$ " (fol. 38 v.) (amar, enseñar); la segunda, "que acaba el infinitivo en $e r$ " (fol. 38 v.) (leer, correr); y la tercera, "que acaba el infinitivo en ir" (fol. $38 \mathrm{v}$.): oír, vivir. Prisciano había recalcado que "sunt igitur coniugationes quattuor apud Latinos, cum apud Graecos decem sint" (H. Keil [ed.], II, p. 442).

${ }^{59}$ G. Correas, Arte, fol. $111 \mathrm{v}$.

${ }^{60}$ G. Correas, Arte, fol. 106 r.

${ }^{61} \mathrm{G}$. Correas, Arte, fol. $106 \mathrm{r}$.

${ }^{62}$ G. Correas, Arte, fol. 106 r.

${ }^{63}$ G. Correas, Arte, fol. 106 r. Como hace notar J. L. Girón Alconchel, "Correas es el gramático más atento y sensible a la variedad interna del idioma; documenta las más importantes variedades diatópicas, diastráticas, diafásicas y diacrónicas de su época. Su norma lingüística se guía por la verborum 
Sobre el pretérito imperfecto de indicativo apunta que, en las conjugaciones segunda y tercera, la $a$ de la terminación suele mudarse en $e$ "por dialecto particular en Castilla la Nueva, Mancha, i Estremadura i partes de Andaluzia"64, diciéndose, sobre todo entre no letrados, "avié, aviés, avié, aviémos, aviedes, avién, dizié, diziés, dizié, quirié, quiriés, quirié, etc., por avia, avias, dezia, dezias, queria, querias, etc." ${ }^{65}, \mathrm{y}$, en la segunda persona del plural, se sincopa la $d$, diciéndose "avieis, harieis, dizieis, quirieis por aviedes, hariedes, etc."

En relación con el pretérito imperfecto de subjuntivo, comenta que, en la forma en -ra (amara), según los casos, "se haze vago de tienpo no señalado" ${ }^{\prime 67}$ como los aoristos griegos (no hubo persona que por él volviera ni hablara), envuelve tiempo futuro "i muestra deseo i se haze optativo" (yo de buena gana estudiara y leyera) o es condicional y expresa tiempo pasado: si él en la mocedad trabajara, no se hallara en la vejez perdido; que, en la forma en -ría (amaría), integrada por la combinación del infinitivo correspondiente y la desinencia $-i a^{68}$, "muestra deseo i futurizion con mas eficazia"69 (yo de buena gana estudiaría y creo que aprovecharía), y que, en la forma en -se (amase), "por la maior parte es condizional con tienpo venidero"70 y le preceden partículas condicionales (si él se aplicase, yo le ayudaría) o modales: como él quisiese, ingenio tiene para el estudio.

En el pretérito perfecto de indicativo, puntualiza que la forma amé "sinifica tienpo cunplido enteramente" ${ }^{, 71}$ (ayer hice); he amado, "pasado inmediato, i arrimado à presente, quanto se á acabado de hazer aora" 72 (hoy he hecho); y hube amado, poco usada por preferirse en pretérito pluscuamperfecto, "pasado con antezedenzia de tienpo i ocasion à otra cosa, o persona" ${ }^{, 73}$, como ya se ha adelantado: cuando él arribó, habia yo descansado ya, y comido.

Por lo que respecta al futuro o venidero de indicativo, subraya que se forma con el infinitivo del verbo correspondiente y el presente de indicativo de haber (amar + $[h] e>$ amaré), a lo que añade que algunos verbos de la segunda y tercera conjugación sincopan la vocal e o $i$ del infinitivo (cabré, pondré o porné, tendré o terné, valdré o, como dicen los rústicos, valré) y que, cuando se deshace la

proprietas, que halla en los usos tradicionales y populares y en la razón" ("Historia de la Gramática en España”, en M. Alvar [dir.], Introducción a la lingüística española, Barcelona, Ariel, 2000, p. 73).

${ }^{64}$ G. Correas, Arte, fol. 106 v.

${ }^{65}$ G. Correas, Arte, fol. 106 v.

${ }^{66} \mathrm{G}$. Correas, Arte, fol. $106 \mathrm{v}$.

${ }^{67}$ G. Correas, Arte, fol. 106 r.

${ }^{68}$ En este punto, el autor hace notar que "se desprenden i apartan las silabas desta forma de la composizion del infinitivo muchas vezes, i se entremete otra palavra, ò palavras en medio" (Arte, fol. 98 v.): si me dieses el libro, leerle ía i volvértele ía.
${ }^{69} \mathrm{G}$. Correas, Arte, fol. $106 \mathrm{v}$.
${ }^{70}$ G. Correas, Arte, fol. $106 \mathrm{v}$.
${ }^{71}$ G. Correas, Arte, fol. 106 v.
${ }^{72}$ G. Correas, Arte, fol. 107 r.
${ }^{73}$ G. Correas, Arte, fol. 107 r. 
composición, se coloca al principio la forma correspondiente de haber y al final el infinitivo, intercalando entre ambos elementos la preposición de: "é de aver, as de aver, é de amar, as de amar, é de leer, as de oir" "74.

Como ya se apuntó anteriormente, el futuro de subjuntivo en Correas comprende tres formas, correspondientes al futuro imperfecto de subjuntivo (amare), al futuro perfecto de indicativo (habré amado) y al futuro perfecto de subjuntivo (hubiere amado), que expresan, respectivamente, un significado "vago i condizional"," "con antizipazión" $" 76$ "condizional con prezedenzia", sincopa en la segunda plural: amaredes, amardes, leierdes, oierdes, quisierdes, vinierdes, mandardes" "78; la segunda "se haze del futuro indicativo avré del verbo aver, i del partizipio ministro" ${ }^{\text {, }}$ y la tercera, "de la primera uviere del verbo aver, $\mathrm{i}$ del partizipio ministro" $" 80$.

En el imperativo, el gramático extremeño solo reconoce las segundas personas del singular y del plural, como en hebreo y caldeo. Frente a los que mezclan personas del presente de subjuntivo en el imperativo, sostiene que no hay razón para ello, ya que el subjuntivo "no manda derechamente, sino persuade, conzede, permite, rruega, i amonesta" ${ }^{\natural 1}$. Lo que sí acepta es que el presente de subjuntivo, a excepción de la primera persona del singular, dado que nadie puede darse órdenes a sí mismo, "es como inperativo, ò sirve como inperativo ò amonestativo" ${ }^{" 2}$. En la segunda persona del plural, señala que, por eufonía, con frecuencia se produce la apocope de la $-d$, considerando recomendable, en tal caso, representar el acento sobre la última vocal (amá, temé, consumi) para mantener la distinción con otros tiempos que no lo llevan. Cuando a la forma con - $d$ se le agregan los pronombres enclíticos le $(s), l a(s), l o(s)$, comenta que "por buen sonido se haze metatesis, i trueco de la $d$ i de la $l$ "83, diciéndose amalde (< amadle), temelde ( $<$ temedle), servildes (servidles).

El maestro Correas explica que el infinitivo de presente, que "tiene una sola persona ò cadenzia comun à las tres personas que hablan en singular i en plural i à todos los tienpos ${ }^{\prime \prime 4}$, termina en ar, er o $\mathrm{ir}$. Cuando se le posponen los enclíticos antes mencionados, observa que la $r$ se asimila a la $l$ (amarle $>$ amalle, quitarles $>$ quitalles, sufrirle $>$ sufrille), destacando que ambas formas son muy usadas. De los infinitivos de pasado y de futuro comenta que se forman perifrásticamente; el de

\footnotetext{
${ }^{74}$ G. Correas, Arte, fol. 107 r.

${ }^{75}$ G. Correas, Arte, fol. 107 r.

${ }^{76}$ G. Correas, Arte, fol. 107 r.

${ }^{77}$ G. Correas, Arte, fol. 107 r.

${ }^{78}$ G. Correas, Arte, fol. 107 r.

${ }^{79}$ G. Correas, Arte, fol. 107 r.

${ }^{80}$ G. Correas, Arte, fol. 107 r.

${ }^{81}$ G. Correas, Arte, fol. 107 v.

${ }^{82}$ G. Correas, Arte, fol. 107 v.

${ }^{83}$ G. Correas, Arte, fol. 107 v.

${ }^{84} \mathrm{G}$. Correas, Arte, fol. $107 \mathrm{v}$.
} 
pasado, con "el infinitivo aver i el partizipio ministro de cada verbo" ${ }^{95}$ (haber amado), y el de futuro, "del infinitivo aver i del infinitivo de cada verbo puesta en medio la preposizion de" " haber de amar, haber de comer, haber de consumir.

El infinitivo de modo y participial, llamado gerundio en la gramática latina (amando), "no limita tienpo, i declara el modo ò manera como algo se haze i suple por los partizipios de Griego, Latin i Hebreo" $" 87$. Los otros dos infinitivos de esta índole formados "por rrodeo" integrados, respectivamente, por la combinación del gerundio de haber y el participio ministro del verbo que se conjugue (habiendo amado) o de "aviendo i del infinitivo de cada verbo puesta en medio la preposizion de" $e^{\text {89: }}$ habiendo de amar.

Sobre el participio de presente, terminado en -ante o en -iente, según las conjugaciones, Correas apunta que en castellano "mui pocas vezes se usa con la fuerza de partizipio con acusativo i transizion despues de si; antes se haze sinple nonbre verbal adxetivo, i à vezes parece sustantivo, como escriviente, oiente, amante, leiente; porque los partizipios se suplen en Castellano con los articulos i esta parte $q u e$, i las personas de los tienpos por todos ellos" ${ }^{\prime 90}$. En lugar del participio de presente latino, indica que se dice, según el tiempo, el que ama, el que amaba, el que amó, etc., pudiendo seguir acusativo, como en el que estima la honra.

En relación con el participio de pasado o pasivo, afirma que "tiene tres terminaziones para los tres generos" ${ }^{\prime 91}$ (amado, amada, amado), subrayando que muchos participios pasados se usan con significación activa, como atrevido 'el que se atreve', entendido 'el que entiende las cosas', callado 'el que calla'. Al no haber participio de futuro, explica que se suple de dos maneras: con el artículo, el relativo que y el futuro imperfecto (el que amará), o con "el artículo i la parte que i el verbo é, ás, con la preposizion de i el infinitivo de cada verbo" ${ }^{92}$ : el que ha de amar.

3. Siguiendo a Nebija, pero enriqueciendo sus puntos de vista con la observación directa del uso de la lengua por los diversos sectores sociales, Correas analiza:

a) Los verbos que contienen intercalado el fonema $/ \mathrm{k} / c$ o $/ \mathrm{g} / \mathrm{g}$ entre la terminación y la raíz en la primera persona del singular del presente de indicativo $\mathrm{y}$ en todas las del presente de subjuntivo ${ }^{93}$ : nazco, nazca; oigo, oiga.

${ }^{85}$ G. Correas, Arte, fol. 107 v.

${ }^{86}$ G. Correas, Arte, fol. 107 v.

${ }^{87} \mathrm{G}$. Correas, Arte, fol. $107 \mathrm{v}$.

${ }^{88}$ G. Correas, Arte, fol. 108 r.

${ }^{89}$ G. Correas, Arte, fol. 108 r.

${ }^{90}$ G. Correas, Arte, fol. 108 r.

${ }^{91}$ G. Correas, Arte, fol. 108 r.

${ }^{92}$ G. Correas, Arte, fol. 108 v.

${ }^{93}$ Nebrija, en las reglas generales quinta y sexta de la formación del verbo, señala: "La quinta regla sea que todos los verbos de la segunda conjugación que acaban en $c o$ i tienen $z$ ante la $c o$, cuando por razón de la conjugación la $o$ final se muda en $e$ o en $i$, echamos fuera la $z$; como crezco, creces, crecí. // La sesta regla sea que todos los verbos de la segunda conjugación que acaban en go, pierden la $g$ en todos 
b) Los verbos que diptongan en ie o en $u e$, respectivamente, la $e$ o la $o$ acentuadas de su raíz en las tres personas del singular y tercera del plural de los presentes de indicativo y subjuntivo, y en la segunda persona del singular del imperativo $^{94}$ : pienso, piense, piensan, piensen, piensa tú; cuento, cuentan, cuenten, cuenta tú.

c) Los verbos de la tercera conjugación que, teniendo $i$ o $u$ en la penúltima sílaba de las personas fuertes del presente de indicativo y en todas las personas de otros tiempos, las truecan, respectivamente, en $e \mathrm{u} o$ en la primera y segunda personas del plural del presente de indicativo, en todo el imperfecto de indicativo, en las formas en -ría del imperfecto de subjuntivo ${ }^{95}$, en las personas primera y segunda del singular y plural del perfecto de indicativo, en todo el futuro de indicativo, en la segunda persona del plural del imperativo, en el infinitivo y en el participio pasado ${ }^{96}$ : pido, pida, pedimos, pedís, pedía, pediría, pedí, pediste, pedistes, pediré, pedid, pedir, pedido; pulo, pula, polimos, polis, polía, poliría, polí, poliste, polistes, poliré, polid, polir, polido.

d) Los verbos con irregularidades no comprendidas en los grupos anteriores: $i r$, caber, saber, ver, añadir ${ }^{97}$.

e) Los pretéritos irregulares: di, estuve, hize, quise, traxe o truxe, pude, supe, cupe, tuve, uve, vi, fui, vine, dixe ${ }^{98}$.

los otros lugares, salvo en aquellos tiempos que se forman del presente del indicativo; como vengo, venía, vine" (Gramática, fol. 62 r.).

${ }^{94}$ Nebrija, en la primera regla general de la formación del verbo, anota: "La primera regla sea que muchos verbos de los que tienen esta letra $e$ en la penúltima sílaba del presente del infinitivo, la vuelven en ie, diphthongo, i algunas vezes en $i$, en ciertos lugares; como de perder, pierdo" (Gramática, fol. 62 r.), y, en la tercera: "La tercera regla sea que muchos verbos de los que tienen esta letra $o$ en la penúltima sílaba del presente del infinitivo, la vuelven en $u$, sueltas i cogidas en una sílaba por diphthongo, i algunas vezes en esta letra $u$ " (Gramática, fol. 62 r.).

${ }^{95}$ Como se ha visto anteriormente, en la Gramática de la Real Academia Española, la forma en -ría se encuentra incluida en el pretérito imperfecto de subjuntivo hasta la edición de 1916, pasando, en la de 1917, a formar el modo potencial.

${ }^{96}$ Nebrija, en la segunda regla general de la formación del verbo, escribe: "La segunda regla sea que los verbos de la tercera conjugación que tienen $e$ en la penúltima sílaba del presente del infinitivo i la vuelven en $i$ en la primera posición del verbo, cuando en la conjugación se sigue otra $i$, bolvemos la $i$ primera en $e$; como de pedir, pido, pedimos" (Gramática, fol. 62 r.).

${ }^{97}$ Nebrija, al tratar la formación del venidero de indicativo, explica que "algunas vezes hazemos cortamiento de letras o transportación dellas en este tiempo, como de saber, sabré, por saberé; de caber, cabré, por caberé; de poder, podré, por poderé; de tener, terné, por teneré; de hazer, haré, por hazeré; de querer, querré, por quereré; de valer, valdré, por valeré; de salir, saldré, por saliré; de aver, avré, por averé; de venir, vendré, por veniré; de decir, diré, por deziré; de morir, morré, por moriré" (Gramática, fol. $64 \mathrm{r}$.), $\mathrm{y}$, al dar cuenta de la formación del subjuntivo, comenta igualmente que "hazemos en este tiempo cortamiento o trasportación de letras en aquellos mesmos verbos en que los hazíamos en el tiempo venidero del indicativo, como de saber, sabria, por sabería; de caber, cabría, por cabería; de poder, podría, por podería; de tener, ternía, por tenería; de hazer, haría, por hazería; de querer, querría, por querería; de valer, valdría, por valería; de aver, avría, por avería; de salir, saldría, por saliría; de venir, vernía, por veniría; de decir, diría, por deziría; de morir, morría, por moriría" (Gramática, fols. 65 r.-65 v.). 
f) Los participios irregulares: abierto, confuso, dicho, hecho, escrito, puesto, roto, visto $^{99}$.

Según el humanista de Jaraíz de la Vera, los verbos en -zco (nazco, merezco, parezco), en la primera persona del singular del presente de indicativo y en todas las del presente de subjuntivo, "tienen por letra formativa la $z$, quitada la silaba $c o$, porque lexitimamente son acabados en $z o$ en el uso antiguo i comun; mas los que se tienen por mas curiosos i bien hablados que el vulgo, estienden la palavra $i$ entremeten la letra $c a^{\text {"100. }}$.

Sobre los verbos caer, traer, huir y oir, apunta que pueden hacer en los presentes de indicativo y subjuntivo caio y caigo, caia y caiga; traio y traigo, traia y traiga; huio y huigo, huia, y huiga; oio y oigo, oia y oiga. En el caso de la primera persona del singular del presente de indicativo del verbo traer, traio, hace notar que "es poco azeta" $" 101$, pero que "los suxuntivos caiga, traia, huia, oia son mas usados"102.

En lo concerniente a los verbos del grupo c), observa que "los antiguos guardaron esta rregla i mudanza mas firme que aora", 103 , pues "ia en algunos pareze mexor seghir la analoghia"104 de la $i$ o de la $u$, diciendo "elixir, escrivir, finxir, rrezibir, eliximos, escrivimos, finxiremos, rrecibimos"105, o "pulir, pulimos, pulis, pulia, puliste, puliere, etc." ${ }^{106}$. De la consideración de estos verbos y los del grupo b) deduce que la $o$ se sustituye "por la $u$ i por la $u e$, i al contrario, i que ansi mesmo la $i$, i la $e$, i la ie se sustituien unas por otras. I por eso muchas veces no se guardan las dichas rreglas, i se dize con las unas ò con las otras"107.

Este "trueco i conversion de unas vocales en otras" $" 108$ no solo se produce en los tiempos y personas del verbo, sino "en todas las tres partes ò palavras de nuestro Castellano"," residiendo la causa del fenómeno en el acento, que "si avia de

\footnotetext{
${ }^{98}$ Nebrija de la formación regular del pasado acabado de indicativo de los verbos de la segunda conjugación exceptúa "algunos que salen en $e$, como de caber, cupe; de saber, supe; de poder, pude; de hazer, hize; de poner, puse; de tener, tuve; de traer, traxe; de querer, quise; de ser, fue; de plazer, pluge; de aver, uve" (Gramática, fol. 63 v.), y de los de la tercera, "algunos que salen en $e$, como de venir, vine; de decir, dixe; de ir, fue" (Gramática, fol. 63 v.).

${ }^{99}$ Nebrija, en la formación del participio y del nombre participial infinito, hace notar que "pocos verbos echan el participio del tiempo passado i el nombre participial infinito en otra manera, como de poner, puesto; de hazer, hecho; de decir, dicho; de morir, muerto; de venir, visto, aunque su compuesto proveer no hizo provisto, sino proveído; de escribir, escripto" (Gramática, fol. 66 v.).

${ }^{100}$ G. Correas, Arte, fol. 112 v.

${ }^{101}$ G. Correas, Arte, fol. 114 v.

${ }^{102}$ G. Correas, Arte, fol. 114 v.

${ }^{103}$ G. Correas, Arte, fol. 116 v.

${ }^{104} \mathrm{G}$. Correas, Arte, fol. $116 \mathrm{v}$.

${ }^{105}$ G. Correas, Arte, fol. 116 v.

${ }^{106}$ G. Correas, Arte, fol. 116 v.

${ }^{107}$ G. Correas, Arte, fol. 116 v.

${ }^{108}$ G. Correas, Arte, fol. 116 v.

${ }^{109}$ G. Correas, Arte, fol. 116 v.
} 
colocarse sobre $e$, ò sobre $o$ las ensancha i convierte en ditongo ié, ué,"110; pero, si las palabras "crezen i se varian i desatan i pasa el azento adelante, buelven aquellos ditongos à su ser i sinples e, o: piedra, pedrada, piel, pellexa, pierna, pernil, tienda, tendero, tienpo, tenporal, zielo, zeleste, bueno, bondad, cuerda, cordel, puente, ponton, puerta, portada, portal, puesto, postura, fuente, fontana, fuego, hogar" "111.

$\mathrm{Al}$ estudiar el verbo ir, Correas indica que antiguamente se decía vo del mismo modo que do, so y estó; pero, "ia por llenar mas la boz"112, se dice voi, como doi, soi y estoi. Sobre las dos formas singulares del imperativo, ve y vai tú, manifiesta que "ve es mas usado, vai se estendió con la $i$, i no le tienen por tan elegante: no le condeno, como ni al inperativo sé de soi, que se alarga, sei tu" ${ }^{13}$.

Apunta, asimismo, que algunos hablantes cortan en is la segunda persona del plural del presente de indicativo, diciendo ¿dónde is? por ¿dónde vais?, y "no solo en esta persona y verbo, sino en todos i en otros tienpos tienen maña de mudar la es final de las segundas plurales en is, como diziendo amavadis, fuistis, venistis, llegastis" 114 , mientras que "otros las alargan en eis, i esto es mas rrezebido i comun en algunas tierras entre xente sin letras, diziendo fuisteis, venisteis, amasteis, veniadeis, venieradeis" $" 115$ e incluso otros "las abrevian en ais, eis, à proporzion del presente: pediais, pedieis, podiais, pudierais, queriais, quisierais, quirieis, amavais, temiais" $" 16$.

Frente las formas quepo y sé, primeras personas del singular del presente de indicativo de caber y saber, comenta que existen en el lenguaje infantil las analógicas cabo y sabo, que le parecen más lógicas que las etimológicas, afirmando en relación con quepo y cabo que "ni de la una manera, ni de la otra se admite en buen uso, ni se escrive" 117 .

La irregularidad del verbo ver se debe, a su juicio, a la pérdida, por síncopa, de la $e$ de la raíz ante las terminaciones que empiecen por esa vocal, que se había conservado en la lengua antigua (veer, veemos, veí, veíste, veído) y en el compuesto proveer: proveemos, proveiste, proveeré. Sobre el verbo añadir anota que "es mui vario en la penultima" "118, ya que se dice añadir, añedir o añidir, variando en los restantes tiempos "como mas les cae"119: añada o añida, añadía o añidia, añadí o añidi, etc.

\footnotetext{
${ }^{110}$ G. Correas, Arte, fol. 117 r.

${ }^{111}$ G. Correas, Arte, fol. 117 r.

${ }^{112}$ G. Correas, Arte, fol. 117 v.

${ }^{113}$ G. Correas, Arte, fol. 117 v.

${ }^{114}$ G. Correas, Arte, fol. 117 v.

${ }^{115}$ G. Correas, Arte, fol. 117 v.

${ }^{116}$ G. Correas, Arte, fol. 117 v.

${ }^{117}$ G. Correas, Arte, fol. 118 r.

${ }^{118}$ G. Correas, Arte, fol. 118 r.

${ }^{119}$ G. Correas, Arte, fol. 118 r.
} 
En el tratamiento de los pretéritos irregulares, el Catedrático de Salamanca no los agrupa por el tipo de irregularidad que presentan, sino por conjugaciones, y observa que casi todos llevan el acento en la "anteultima" ${ }^{20}$ sílaba, es decir, en el tema, no en la terminación, como los regulares, y que la tercera persona del plural se forma "vulgarmente" 121 añadiendo $-n$ a la del singular por "analogia de los otros tienpos"122: estuvo, estuvon; anduvo, anduvon; hizo, hizon; quiso o quix, quison o quixon; traxo o truxo, traxon o truxon; pudo, pudon; tuvo, tuvon; puso, puson; plugo, plugon; cupo, cupon; dixo, dixon; vido, vidon; vino, vinon.

Sobre el pretérito fui apunta que en la lengua antigua se conjugaba fue, fueste, fue, fuemos, fuestes, fueron, y que, si estas formas no hubieran caído en desuso, podrían emplearse como perfecto del verbo $i r$, dejando las modernas para ser, con lo que se hubieran evitado confusiones. Por otro lado, indica que al perfecto irregular siguen el futuro imperfecto de subjuntivo y las formas en - $r a$ y $-s e$ del pretérito imperfecto de este mismo modo.

En el grupo de los participios irregulares, observa que hay cinco que:

...tienen una curiosa y necesaria notazion i uso, que el partizipio ministro se usa formado de los rregulares con el verbo é, as para hazer los rrodeos de los tienpos que se suplen con ellos, ansi: é confundido, as confundido; é infundido, as infundido; é despertado, as despertado; é desdezido del valor i ser de antes, ase desdezido de su palavra; é soltado, as soltado. No se dirá é confuso, é infuso, é despierto, é suelto ${ }^{123}$.

Los niños y algunas personas mayores "por grazia i xughete, i à vezes con descuido sin rreparar en mas de dezir su conzeto" ${ }^{24}$ forman estos participios regularmente "por analoghia" 125 .

4. De lo expuesto en las páginas precedentes se deduce que la doctrina gramatical de Correas sobre el verbo, en la línea emprendida por Dionisio de Tracia y seguida por los gramáticos latinos, principalmente Prisciano, se encuentra en buena medida influenciada por la de Nebrija. Formulada por el gramático extremeño en un orden diferente y con mayor amplitud que el andaluz, interesa sobre todo por su claridad y riqueza de pormenores, por la atención prestada a las formas populares y dialectales, y por destacar a menudo su vigencia en la época y su rango social. Además de ejercer una clara influencia en la tradición gramatical española, en algunos casos, con las

${ }^{120}$ G. Correas, Arte, fol. 117 v.

${ }^{121}$ G. Correas, Arte, fol. 117 v.

${ }^{122}$ G. Correas, Arte, fol. 117 v.

123 G. Correas, Arte, fol. 119 r. No obstante, se indica que suelto "podría usarse, como los compuestos é rresuelto, é disuelto el matrimonio" (Arte, fol. 119 r.).

${ }_{24}$ G. Correas, Arte, fol. 119 r.

${ }^{125}$ G. Correas, Arte, fol. 119 r. 
lógicas diferencias derivadas del contexto en el que se encuentra inmerso, el autor del Arte de la lengua española castellana se adelanta en determinados aspectos a ciertos postulados de la lingüística moderna..

\section{Bibliografía}

Alarcos Llorach, E. (1994): Gramática de la lengua española, Madrid, Real Academia Española, Colección Nebrija y Bello, Espasa Calpe.

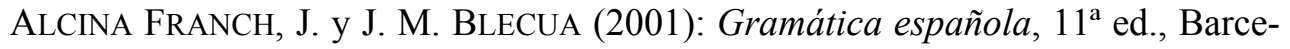
lona, Ariel.

ARNAULD, A. y C. LANCELOT (1966): Grammaire générale et raisonnée, Stuttgart-Bad Cannstatt, F. F. Verlag.

Bello, A. (1988): Gramática de la lengua castellana destinada al uso de los americanos. Con las Notas de R. J. Cuervo. Estudio y edición de R. Trujillo, Madrid, Arco/Libros.

CALERO VAQUeRA, Ma L. (1986): Historia de la gramática española (18471920), Madrid, Gredos.

CORREAS, G. (1627): Trilingüe de tres artes de las tres lenguas castellana, latina $i$ griega, todas en romanze, Salamanca, A. Ramirez.

CORREAS, G. (1954): Arte de la lengua española castellana. Edición y prólogo de E. Alarcos García, Madrid, CSIC, Instituto "Miguel de Cervantes", Anejo LVI de la $R F E$.

GIRÓN ALCONCHEL, J. L. (2000): "Historia de la Gramática en España”, en M. Alvar (dir.), Introducción a la lingüistica española, Barcelona, Ariel, pp. 69-91.

GómeZ ASENCiO, J. J. (1981): Gramática y categorías verbales en la tradición española (1771-1847), Ediciones Universidad de Salamanca.

GómeZ ASENCIO, J. J. (1985): Subclases de palabras en la tradición española (1771-1847), Ediciones Universidad de Salamanca.

HERNANDO GARCÍA-CERVIGÓN, A. (2006): "El verbo y las partes invariables de la oración en el Dictamen de la Comisión de Gramática (1861) de la Real Academia Española", Revista de Filología Románica, 23, pp. 13-28.

KeIL, H. (ed.) (1981): Grammatici Latini, Hildesheim - New York, G. Olms.

LAllot, J. (1989): La grammaire de Denys le Thrace, Paris, Éditions du Centre National de la Recherche Scientifique.

LÁzAro Mora, F. A. (1981): La presencia de Andrés Bello en la Filología Española, Ediciones Universidad de Salamanca.

NeBriJA, A. de (1992): Gramática de la lengua castellana. Edición crítica de A. Quilis, Madrid, Ediciones de Cultura Hispánica.

NEBRIJA, A. de (1996): Introducciones latinas contrapuesto el romance al latín [c. 1488]. M. A. Esparza \& V. Calvo (eds.), Münster, Nodus Publikationen. 
RAMAJO CAÑO, A. (1987): Las gramáticas de la lengua castellana desde Nebrija a Correas, Ediciones Universidad de Salamanca.

REAL ACADEMIA ESPAÑOla (1771): Gramática de la lengua castellana, Madrid, Por D. J. de Ibarra, Impresor de Cámara de S. M.

REAL ACADEMIA ESPAÑOLA (1867): Gramática de la lengua castellana, Madrid, Imprenta de M. Ginesta.

REAL ACADEMIA ESPAÑOla (1870): Gramática de la lengua castellana, Madrid, Imprenta y estereotipia de M. Rivadeneyra.

REAL ACADEMIA ESPAÑola (1916): Gramática de la lengua castellana, Madrid, Perlado, Páez y Compañía (Sucesores de Hernando), Impresores y Libreros de la Real Academia Española.

REAL ACADEMIA ESPAÑOLA (1917): Gramática de la lengua castellana, Madrid, Perlado, Páez y Compañía (Sucesores de Hernando), Impresores y Libreros de la Real Academia Española.

REAL ACADEMIA ESPAÑOLA (1973): Esbozo de una nueva gramática de la lengua española, Madrid, Espasa Calpe.

REAl ACADEMIA ESPAÑOla y ASOCIACiÓn DE ACADEMIAS DE LA LENGUA ESPAÑOLA (2009): Nueva gramática de la lengua española, Madrid, Espasa Calpe.

RoBINS, R. H. (1992): Breve historia de la Lingüistica, 6 a ed., Madrid, Paraninfo.

SALVÁ, V. (1988): Gramática de la lengua castellana según ahora se habla. Estudio y edición de M. Lliteras, Madrid, Arco/Libros.

SÁNCHEZ DE LAS BROZAS, F. (1995): Minerva o De causis linguae latinae (1587). Introducción y edición de E. Sánchez Salor (Libri I, III y IV); edición de C. Chaparro Gómez (Liber II), Cáceres, Institución Cultural "El Brocense", Excma. Diputación Provincial de Cáceres y Universidad de Extremadura.

Villalón, C. de (1971): Gramática castellana. Edición facsimilar y estudio por C. García, Madrid, CSIC. 